\title{
Mineralocorticoid receptor antagonism inhibits vein graft remodeling in mice
}

\author{
Afshin Ehsan, MD, ${ }^{\text {acc }}$ Adam P. McGraw, PhD,${ }^{\mathrm{c}}$ Mark J. Aronovitz, MS, ${ }^{\mathrm{c}}$ Carol Galayda, BS, ${ }^{\mathrm{c}}$ \\ Michael S. Conte, MD, ${ }^{\mathrm{d}}$ Richard H. Karas, MD, PhD, ${ }^{\text {b,c }}$ and Iris Z. Jaffe, MD, $\mathrm{PhD}^{\mathrm{b}, \mathrm{c}}$
}

Objective: Vein graft failure rates resulting from adverse graft remodeling remain high with no effective therapy. The mineralocorticoid receptor (MR) plays a role in pathologic arterial remodeling. We demonstrated recently that the MR is upregulated in venous tissues after grafting and hypothesized that MR inhibition would reduce vein graft remodeling.

\begin{abstract}
Methods: Reverse transcription polymerase chain reaction and immunoblotting were used to examine the expression of the MR and other components of the renin-angiotensin-aldosterone system in human vein and primary human saphenous vein smooth muscle cells (HSVSMC). Adenoviral reporter gene assays were used to explore MR transcriptional activity in HSVSMC. The effect of MR inhibition on vein graft remodeling in vivo was characterized in a mouse vein graft model.
\end{abstract}

Results: Messenger RNAs encoding the MR, 11- $\beta$-hydroxysteroid dehydrogenase 2, angiotensin type 1 receptor, and the angiotensin-converting enzyme are expressed in whole HSVSMC. MR and 11- $\beta$-hydroxysteroid dehydrogenase 2 protein expression is confirmed, and MR-dependent transcriptional regulation is demonstrated at physiologic aldosterone concentrations in HSVSMC. Treatment of mice with the MR antagonist spironolactone, at doses that do not lower blood pressure $(20 \mathrm{mg} / \mathrm{kg}$ per day), reduces maximal vein graft intima-media thickness by $68 \%$, with an associated reduction in graft inflammatory cell infiltration and fibrosis.

Conclusions: MR is expressed in human venous tissue and cells and modulates gene expression in HSVSMC in response to physiologic aldosterone concentrations. In vivo, MR inhibition reduces vein graft thickening and inflammation. These preclinical data support the potential to use MR antagonists as novel treatments to preserve vein graft patency. (J Thorac Cardiovasc Surg 2013;145:1642-9)

Supplemental material is available online.

Bypass surgery remains an important therapeutic option for patients with arterial occlusive disease; however, vein graft failure rates resulting from adverse graft remodeling remain high with no effective therapy. Veins placed in the arterial circulation undergo adaptive remodeling with rapid smooth muscle cell (SMC) hyperplasia, thereby reducing wall tension. ${ }^{1}$ The mechanism involves medial SMC

From the Divisions of Cardiothoracic Surgery ${ }^{\mathrm{a}}$ and Cardiology ${ }^{\mathrm{b}}$ and the Molecular Cardiology Research Institute, ${ }^{\mathrm{c}}$ Tufts Medical Center, Boston, Mass; and the Division of Vascular Surgery, ${ }^{\mathrm{d}}$ University of California at San Francisco, San Francisco, Calif.

This work was funded by National Institutes of Health grant HL095590 to I.Z.J. and American Heart Association grant 11POST5390010 to A.P.M.

Disclosures: Authors have nothing to disclose with regard to commercial support.

A.E. and A.P.M. contributed equally to this work.

Received for publication June 12, 2012; revisions received July 20, 2012; accepted for publication Aug 1, 2012; available ahead of print Sept 17, 2012.

Address for reprints: Iris Z. Jaffe, MD, PhD, Tufts Medical Center, Molecular Cardiology Research Institute, 800 Washington St, Box 80, Boston, MA 02111 (E-mail: ijaffe@tuftsmedicalcenter.org).

0022-5223/\$36.00

Copyright (c) 2013 by The American Association for Thoracic Surgery

http://dx.doi.org/10.1016/j.jtcvs.2012.08.007 dedifferentiation from a contractile phenotype into a synthetic state that proliferates and secretes cytokines and growth factors, which contribute to a robust inflammatory response. ${ }^{2}$ This process leads to histologic changes resembling those seen in arterial atherosclerosis, including the development of inflamed focal lesions that can occlude blood flow or rupture, leading to thrombus formation. . $^{3,4}$ The pathologic changes found in failed vein graft specimens removed from patients undergoing corrective reintervention have also been demonstrated in mouse models of vein grafting, providing a small-animal model to test potential therapies. ${ }^{3,5}$

The mineralocorticoid receptor (MR) is a hormoneactivated transcription factor that modulates gene expression when activated. ${ }^{6}$ The MR is the terminal component of the renin-angiotensin-aldosterone system (RAAS) that is activated in response to hypotension, resulting in production of angiotensin II by the angiotensin-converting enzyme (ACE), which promotes adrenal gland aldosterone release via angiotensin type 1 receptors (AT1Rs). The MR is activated by the steroid hormones aldosterone or cortisol with equal affinity, but the presence of the cortisolinactivating enzyme $11-\beta$-hydroxysteroid dehydrogenase$2(11 \beta \mathrm{HSD} 2)$ confers aldosterone specificity for the MR in tissues where they are coexpressed. ${ }^{6}$ The MR is most well 


\section{Abbreviations and Acronyms \\ $11 \beta \mathrm{HSD} 2=11-\beta$-hydroxysteroid dehydrogenase- 2 \\ ACE = angiotensin-converting enzyme \\ $\mathrm{AT} 1 \mathrm{R}=$ angiotensin type 1 receptor \\ $\mathrm{Ct}=$ cycle threshold \\ DMEM $=$ Dulbecco's Modified Eagle Medium \\ $\mathrm{H} \& \mathrm{E}=$ hematoxylin \& eosin \\ HSVSMC $=$ human saphenous vein smooth muscle cell \\ IVC = inferior vena cava \\ MR = mineralocorticoid receptor \\ mRNA $=$ messenger ribonucleic acid \\ RAAS = renin-angiotensin-aldosterone system \\ SMC $=$ smooth muscle cell}

studied in the kidney, where it raises blood pressure when activated by enhancing renal sodium absorption. ${ }^{6}$ However, our group and others have demonstrated that arterial SMC and endothelial cells express the MR, which contributes to arterial remodeling with enhanced vascular inflammation, fibrosis, and SMC hyperplasia. ${ }^{6-8}$ We demonstrated recently that both the MR and $11 \beta \mathrm{HSD} 2$ are upregulated after grafting in a rabbit vein graft model and also in failing saphenous vein grafts explanted from humans, suggesting a potential role for venous MR in vein graft failure. ${ }^{9}$ Here, we characterize further the expression and function of the RAAS in human venous tissue and cells and explore the role of MR antagonism as a potential therapy to prevent adverse remodeling in a mouse model of vein grafting.

\section{METHODS}

\section{Reagents and Cell Lines}

Aldosterone and spironolactone (Sigma, St Louis, Mo) were resuspended in dimethylsulfoxide, diluted in Dulbecco's Modified Eagle Medium (DMEM; Gibco, Grand Island, NY), and used at the indicated concentrations with corresponding vehicle controls. With approval from the Tufts institutional review board, deidentified samples of discarded human venous tissues that had been harvested endoscopically from patients undergoing indicated coronary artery bypass graft surgery were collected. Primary human vein SMCs were isolated from saphenous vein specimens as described. ${ }^{10}$ For gene expression studies, primary cells were grown in $10 \%$ bovine serum (HyClone, Logan, Utah) in DMEM and were used between passages 3 and 7 .

\section{Quantitative Reverse Transcription-Polymerase Chain Reaction}

Total RNA was isolated from cells or tissue, reverse transcribed, and quantitative polymerase chain reaction was performed as described previously ${ }^{11}$ using primers listed in Table E1. Genes with raw cycle threshold $(\mathrm{Ct})$ values of $\geq 35$ cycles were considered not to be expressed. The $\mathrm{Ct}$ values of expressed genes were normalized to glyceraldehyde-3-phosphate dehydrogenase. Data are represented as the mean normalized expression $\left(2^{-\Delta \mathrm{Ct}}\right)$ in RNA isolated from 4 independent tissue or cell sources each analyzed in duplicate.

\section{Immunoblotting}

Cell lysates were prepared as described previously. ${ }^{7}$ Cell lysates $(1 \mu \mathrm{L}$ control HEK293 cell lysate overexpressing MR or $11 \beta \mathrm{HSD} 2,30 \mu \mathrm{L}$ denatured human saphenous vein SMC (HSVSMC) supernatant for MR immunoblots, and $50 \mu \mathrm{L}$ of the resuspended pellet for $11 \beta \mathrm{HSD} 2$ immunoblots) were separated by $10 \%$ sodium dodecyl sulfate polyacrylamide gel electrophoresis, transferred to $0.45-\mu \mathrm{m}$ nitrocellulose membranes, immunoblotted with monoclonal antibodies raised against the unique MR N-terminus (generous gift from Celso Gomez-Sanchez) ${ }^{12}$ or the $11 \beta$ HSD2 C-terminal catalytic domain (Alpha Diagnostic International, San Antonio, Tex), and visualized by standard chemiluminescence techniques as described previously. ${ }^{7}$

\section{Luciferase Assay}

HSVSMC were serum starved in DMEM for 24 hours, then infected with an adenovirus containing a fused mineralocorticoid responsive element-firefly luciferase construct ${ }^{9}$ at a multiplicity of infection of 200, as described previously. ${ }^{7}$ After infection, cells were grown in DMEM with $5 \%$ charcoal-stripped fetal bovine serum (Atlanta Biologicals, Lawrenceville, Ga) containing vehicle or the indicated hormones for 18 hours. Luciferase activity was determined as described previously. ${ }^{7}$ Luciferase units for each sample were normalized to the value obtained for the vehicle-treated sample for a given experiment to generate the reported fold-change in luciferase activity $(n=3-4$ independent experiments, each in duplicate).

\section{Mouse Inferior Vena Cava-to-Aorta Vein Graft Model}

Animals were handled in accordance with National Institutes of Health standards, and all procedures were approved by the Tufts Medical Center Institutional Animal Care and Use Committee. The inferior vena cava (IVC) from a donor male 12- to 16-week-old inbred, wild-type C57BL6 mouse (Jackson Laboratories, Bar Harbor, Me) was grafted into the abdominal aorta of an equivalent recipient mouse as described previously. ${ }^{5}$ After verifying sufficient blood flow through the graft by in vivo microscopy, recipient mice were randomized to receive a spironolactone $(20 \mathrm{mg} / \mathrm{kg}$ per day)- or placebo-releasing drug pellet (Innovative Research of America, Sarasota, Fla; $\mathrm{n}=8$ per treatment). We and others have demonstrated that at this low dose, spironolactone does not change mouse systolic or diastolic tail cuff blood pressure (data not shown ${ }^{13}$ ). Early graft thrombosis (within 24 hours) requiring euthanasia occurred in some mice, with a survival rate at 4 weeks that was unchanged between the 2 treatment groups. After 4 weeks, the grafted and native IVC were harvested ( $n=4$ per group), fixed in 10\% neutral-buffered formalin, and embedded in paraffin for subsequent immunohistochemical analyses. ${ }^{10}$

\section{Immunohistochemistry}

Sections of embedded vessels were collected at $200-\mu \mathrm{m}$ intervals covering the central $1.6 \mathrm{~mm}$ of the graft, yielding 8 sections spanning approximately $60 \%$ of the total graft length. Serial parallel sections were stained with hematoxylin \& eosin (H\&E), trichrome stain, and smooth muscle-specific alpha actin antibody as described. ${ }^{14}$ The area of the vessel intima and media was quantified from H\&E-stained sections using ImagePro 6.2 software (Media Cybernetics, Rockville, Md). Vessel extracellular matrix content was quantified in trichrome-stained sections and expressed as the absolute intima-media extracellular matrix area. For mononuclear and polymorphonuclear cell quantification, nuclei were counted manually in H\&E-stained sections. Serial sections stained with an anti-smooth muscle alpha actin antibody were used to count the number of actin-positive cells and actin-positive area within the grafted vessel wall. All histological quantifications were performed by a treatment-blinded investigator and reported for the section with the thickest intima-media area for each mouse. 


\section{Statistical Analysis}

Values are reported as mean \pm standard error of the mean. Statistical comparisons were made by $t$ test, 1- or 2 -factor analysis of variance when appropriate with the Student-Newman-Keuls or Mann-Whitney post test using SigmaPlot 11.0 (Systat Software, Chicago, Ill). A value of $P<.05$ was considered significant.

\section{RESULTS \\ Expression of RAAS Genes in Human Saphenous Vein Tissue and SMCs}

Total RNA was isolated from human saphenous vein samples collected from the operating room and from lowpassage primary cultured HSVSMC ( $\mathrm{n}=4$ of each), and quantitative reverse transcription-polymerase chain reaction was performed using primers specific to genes encoding components of the RAAS. Figure $1, A$ demonstrates that the MR, glucocorticoid receptor, $11 \beta \mathrm{HSD} 2$, ACE-1, and AT1R messenger RNAs (mRNAs) are indeed expressed in human saphenous vein tissue and HSVSMC from male and female patients with varied cardiac risk factors undergoing cardiac bypass surgery, whereas renin and aldosterone synthase mRNA are not detected. MR and $11 \beta \mathrm{HSD} 2$ protein expression was examined in cell lysates from primary cultured HSVSMC. Immunoblotting revealed the characteristic $107-\mathrm{kDa}$ MR protein band and the $41-\mathrm{kDa}$ $11 \beta \mathrm{HSD} 2$ protein band, as demonstrated by comparison with overexpressed proteins (positive $[+]$ and negative $[-]$ control lanes on the same immunoblot; Figure 1, $B$ ). These data support the potential for MR to be activated by aldosterone in HSVSMC.

\section{Endogenous MR in HSVSMC Is Activated Transcriptionally by Physiologic Aldosterone Concentrations}

Steroid hormones modulate cellular physiology by binding to steroid receptors to regulate gene expression. We have demonstrated previously that MR in HSVSMC can modulate gene transcription when activated by pathologic aldosterone concentrations, as seen in patients with congestive heart failure $(10 \mathrm{nM})^{6}$; however, most vein graft patients have normal serum aldosterone levels $(\sim 1 \mathrm{nM})$. A sensitive adenoviral reporter of MR-mediated gene expression was used to explore the dose-response relationship of aldosterone activation of HSVSMC MR. Gene expression was activated by aldosterone in a dose-dependent manner beginning at a concentration of $1 \mathrm{nM}$ (Figure 2, A), consistent with physiologic aldosterone levels ${ }^{15}$ and the known dissociation constant of the MR for aldosterone binding. ${ }^{6}$ Treatment of cells with aldosterone in the presence of the MR antagonist spironolactone inhibited aldosterone-dependent transcriptional activation (Figure 2, $B$ ), which supports that transcriptional activation by aldosterone is mediated by endogenous MR in HSVSMC. These data support the potential for MR to be activated

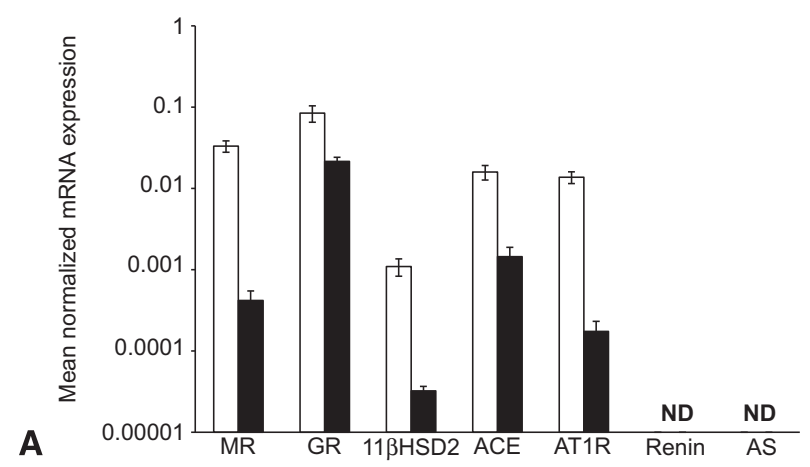

B

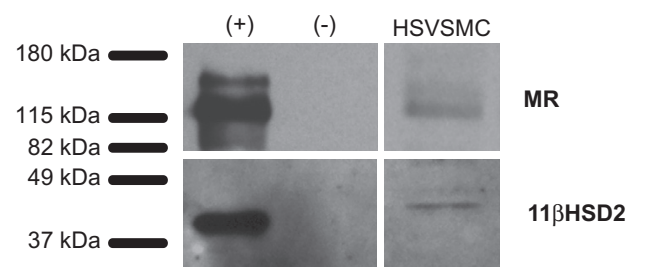

FIGURE 1. Expression of renin-angiotensin-aldosterone system (RAAS) components in human saphenous vein tissue and smooth muscle cells (HSVSMC). A, Quantitative reverse transcription-polymerase chain reaction was conducted to identify RAAS gene messenger RNA (mRNA) isolated from human saphenous vein (white bars) and HSVSMC (black bars). $\mathrm{n}=4$. B, Immunoblots on HSVSMC lysates with antibody specific for mineralocorticoid receptor (MR; top) and $11-\beta$-hydroxysteroid dehydrogenase-2 (11 $\beta$ HSD2; bottom) protein. Lysate from HEK293 cells transfected with empty plasmid $(-)$ or with plasmid that expresses MR or $11 \beta \mathrm{HSD} 2(+)$ serve as negative and positive controls, respectively. $N D$, Not detected; $G R$, glucocorticoid receptor; $A C E$, angiotensin-converting enzyme; $A T 1 R$, angiotensin type 1 receptor; $A S$, aldosterone synthase; $M R$, mineralocorticoid receptor.

transcriptionally in saphenous vein SMC by relevant circulating aldosterone levels found in vein graft patients and could therefore play a role in vein graft remodeling in vivo.

\section{MR Inhibition With Spironolactone Attenuates Vein Graft Remodeling in Vivo}

Using a mouse model of IVC-to-aorta interposition grafting, we investigated the effects of MR inhibition on vein graft remodeling. At the time of vein grafting, mice were randomized to treatment with placebo or to the clinically available MR antagonist spironolactone $(20 \mathrm{mg} / \mathrm{kg}$ per day, a dose that does not reduce blood pressure significantly [data not shown and $\left.{ }^{13}\right]$ ). The native (ungrafted) and grafted IVC were harvested, and graft remodeling was characterized histologically after 4 weeks, a time point when significant vessel remodeling and inflammation have been observed in multiple animal models of vein grafting 5,16 and in humans. ${ }^{17}$ In both treatment groups, the grafted IVC exhibited dramatic remodeling with pathology similar to that seen in human vein grafts, including substantial vessel thickening (Figure 3) and SMC hyperplasia (Figure 4) 


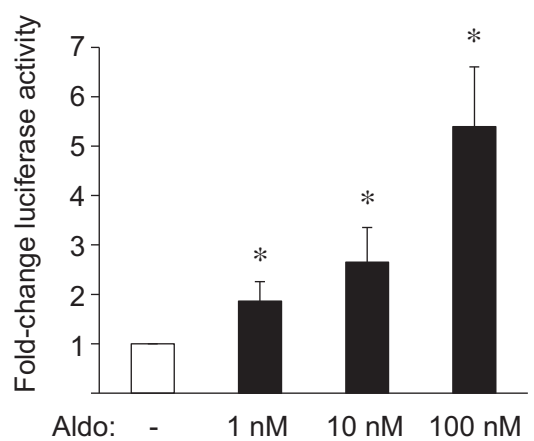

A

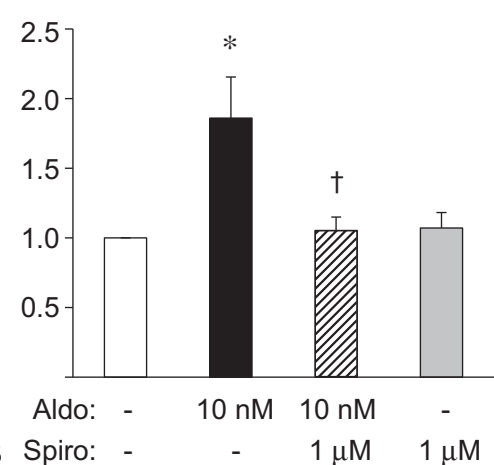

B Spiro: - $\quad-1 \mu \mathrm{M} 1 \mu \mathrm{M}$

FIGURE 2. Functional mineralocorticoid receptor (MR) in human saphenous vein smooth muscle cells (HSVSMC). Primary HSVSMC were infected with an adenovirus containing a mineralocorticoid-inducible response element-luciferase transcriptional reporter. A, Infected cells were treated with increasing doses of aldosterone (Aldo), and Aldo-induced changes in luciferase activity were measured. B, Cells were treated with $10 \mathrm{nM}$ Aldo and/or the MR antagonist spironolactone (Spiro). Dash indicates reagents not added. $* P<.05$ versus vehicle. $\dagger P<.05$ versus $10 \mathrm{nM}$ Aldo.

when compared with the native IVC. Spironolactone treatment resulted in a $68 \%$ reduction in the maximal graft intima-media thickness (Figure 3). The degree of SMC hyperplasia was quantified in sections stained with smooth muscle-specific actin antibody. Despite decreased total graft thickness, there is no difference in the degree of SMC hyperplasia as measured by smooth muscle actinpositive area and the number of SMCs in vein grafts from spironolactone-treated mice (Figure 4). Vein graft fibrosis was also quantified in trichrome-stained sections from the
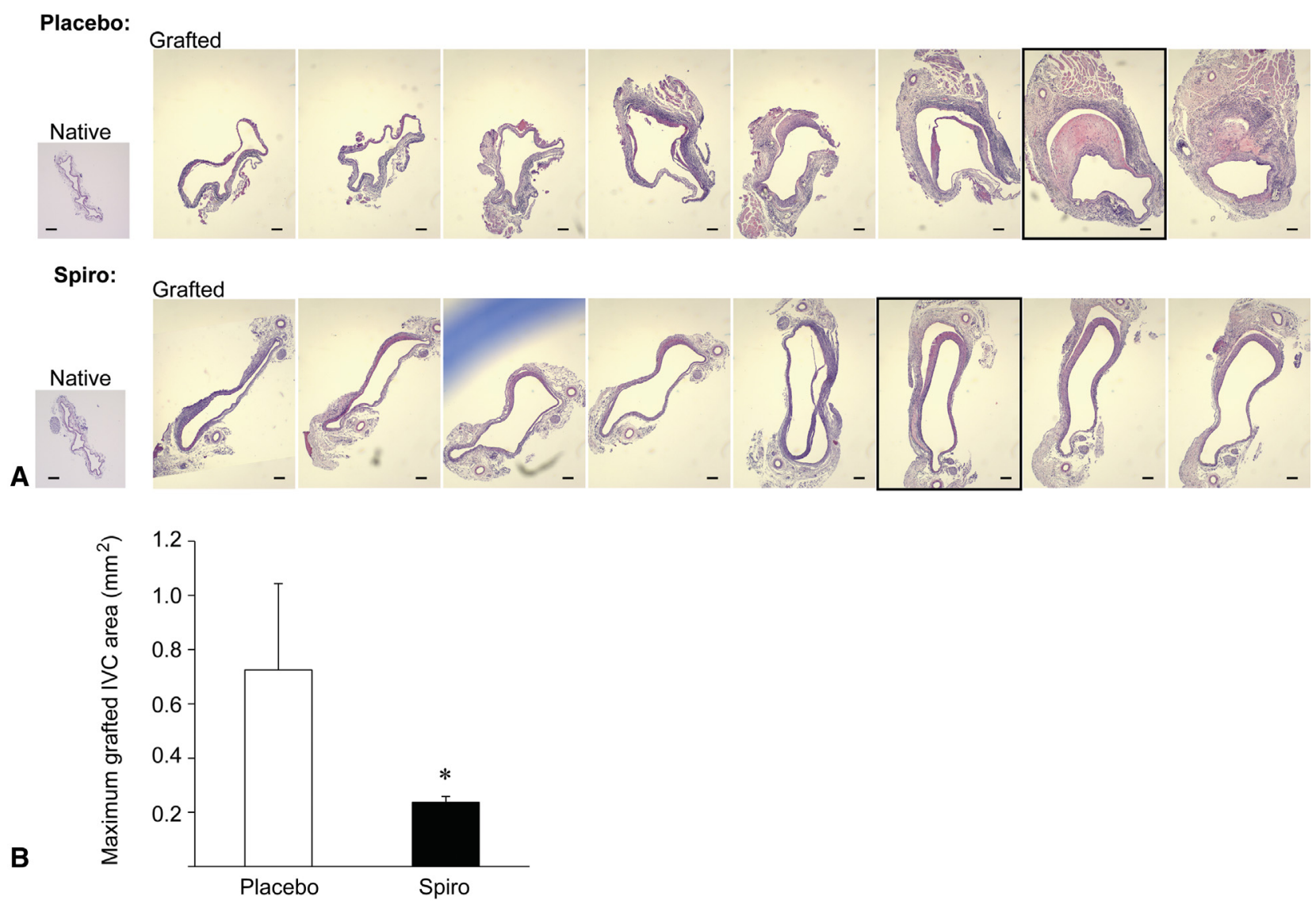

FIGURE 3. Mineralocorticoid receptor antagonism reduces vein graft thickening in mice. A, Representative hematoxylin \& eosin-stained sections from the native inferior vena cava (IVC) and throughout the grafted IVC from placebo- and spironolactone (Spiro)-treated mice. Images are arranged from proximal (left) to distal (right) orientation. Scale bar $=0.1 \mathrm{~mm}$. B, Quantification of the intima-media area of the section with maximal vessel thickness (black boxes) in A from placebo- (white bar) and Spiro-treated (black bar) mice. $* P<.05$ versus placebo. 

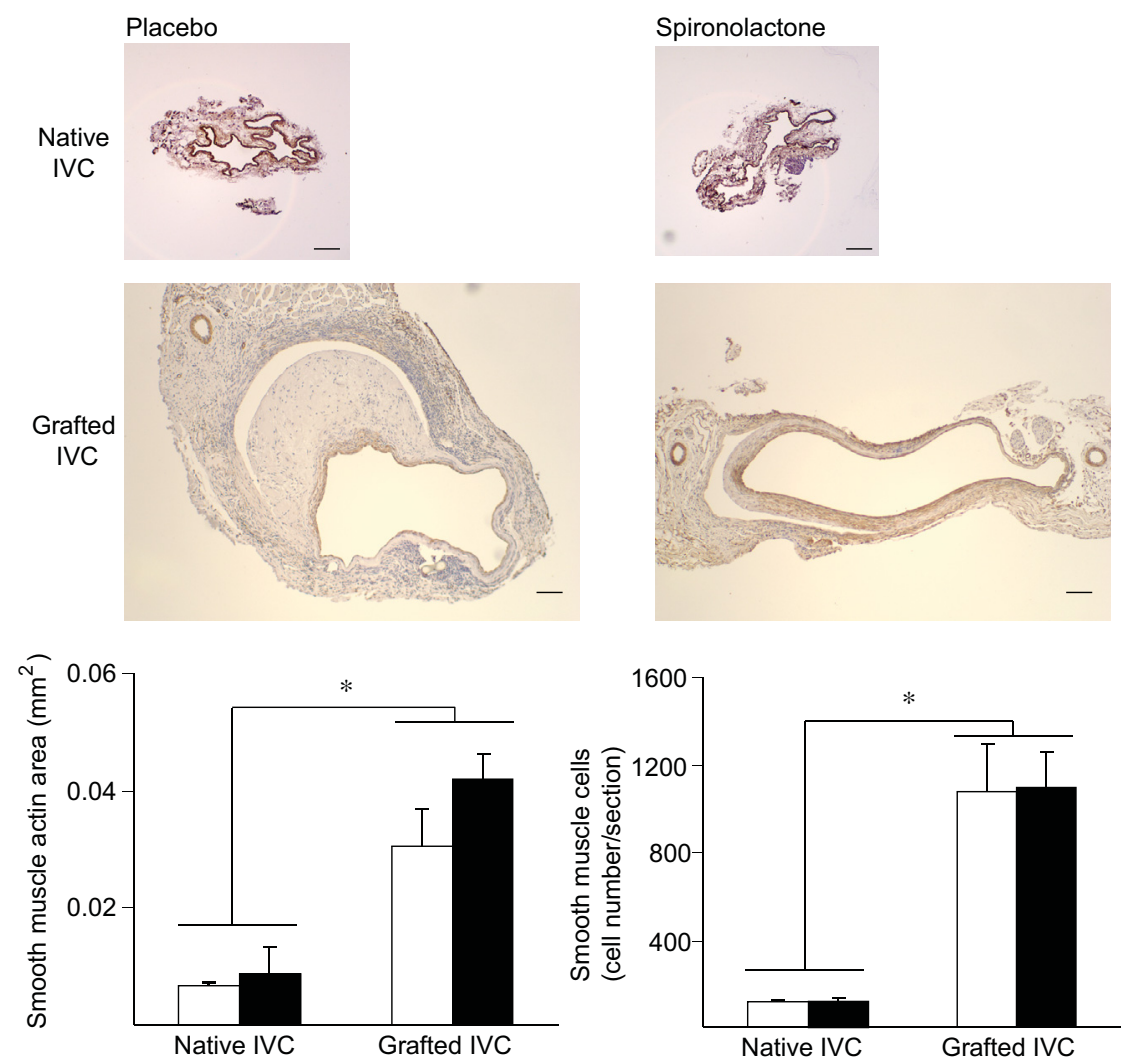

FIGURE 4. Vein graft smooth muscle cell (SMC) hyperplasia with mineralocorticoid receptor antagonism. Immunohistochemical staining of native and grafted inferior vena cava (IVC) sections using SMC-specific $\alpha$-actin antibody. Actin-positive area and nuclei count in SMC actin-positive regions are quantified in vein sections from spironolactone-treated animals (black bars) and placebo-treated animals (white bars). Scale bar $=0.1 \mathrm{~mm}$. $* P<.05$ versus placebo.

area of maximal thickness. Spironolactone treatment reduced the vessel intima-media collagen area by $53 \%$ (Figure 5, A). These data support that MR antagonism does not alter the extent of SMC hyperplasia in response to grafting, but rather attenuates the degree of fibrosis in the grafted veins. The number of inflammatory cells in the grafted vessel wall was quantified by examining serial sections under high magnification $(40 \times)$. Inflammatory cells were counted based on nuclear morphology on $\mathrm{H} \& \mathrm{E}$-stained sections, revealing a 3-fold reduction in polymorphonuclear inflammatory cells in the grafts of animals treated with spironolactone, with no difference in the number of mononuclear inflammatory cells (Figure 5, B).

\section{DISCUSSION}

In this study, we demonstrate that human venous tissue expresses MR and other components of the RAAS, and that MR in HSVSMC is active transcriptionally at physiologically relevant aldosterone concentrations. Moreover, in a mouse model of vein grafting, MR antagonism with the clinically available drug spironolactone prevents vein graft remodeling with significant reductions in maximal graft thickening, total graft fibrosis, and graft inflammation.
The responsiveness of the vasculature to aldosterone has been controversial and relatively unexplored in the venous system. Here we demonstrate that the RAAS components MR, glucocorticoid receptor, $11 \beta \mathrm{HSD} 2, \mathrm{ACE}$, and AT1R are all expressed in human saphenous vein and cultured HSVSMC isolated from individuals with diverse cardiac risk factors. The finding that $11 \beta \mathrm{HSD} 2 \mathrm{mRNA}$ and protein are expressed in HSVSMC supports that human venous SMCs, like arterial SMCs, ${ }^{7}$ also have the potential to respond to aldosterone, although the potential for cortisol to activate venous SMC MR under certain circumstances cannot be ruled out. In addition, MR and 11 $\beta$ HSD 2 are upregulated in failed human vein grafts, suggesting that aldosterone-mediated MR signaling may be enhanced during graft failure. ${ }^{9}$ The role of local vascular aldosterone production remains controversial. ${ }^{6}$ The absence of aldosterone synthase mRNA in venous tissue and cells supports that MR activation in venous cells, as in arterial SMC, ${ }^{7}$ is likely dependent on extravascular sources of aldosterone. We have demonstrated previously that angiotensin II, acting via the AT1R, can also activate MR directly in human arterial SMCs and that aldosterone can regulate AT1R expression in saphenous veins. ${ }^{7,9}$ Thus, the presence of AT1R 

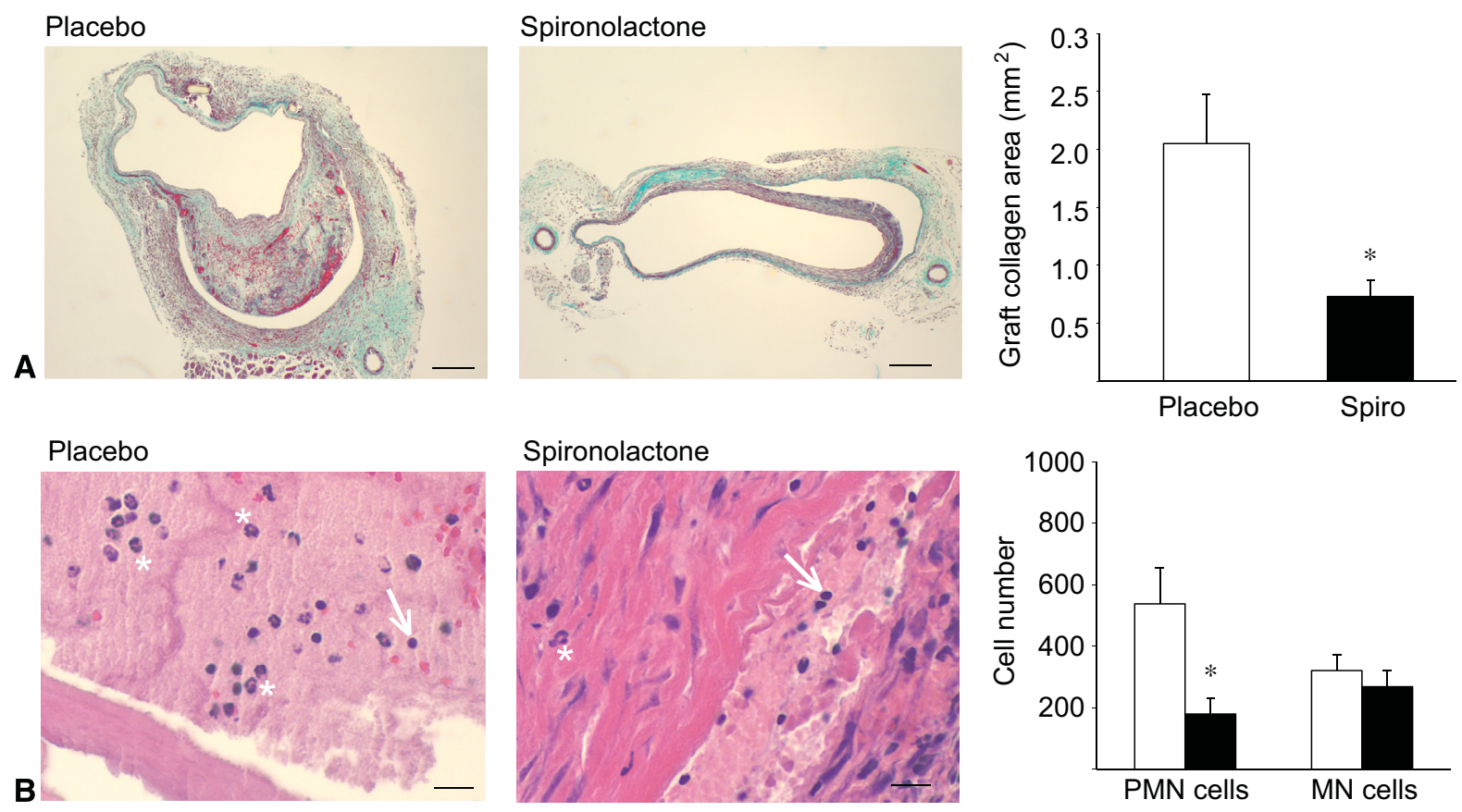

FIGURE 5. Inhibition of the mineralocorticoid receptor reduces vein graft fibrosis and inflammation. A, Quantification of vein graft trichrome-stained collagen area on the thickest sections from placebo- (white bars) and spironolactone (Spiro)-treated (black bars) mice. Scale bar $=0.1 \mathrm{~mm}$. B, Quantification of inflammatory cells in high-power $(40 \times)$ images of hematoxylin \& eosin-stained sections of placebo- and spironolactone-treated animals. Representative mononuclear $(M N)$ cells are indicated by white arrows; polymorphonuclear $(P M N)$ cells are indicated by white asterisks. Scale bar $=0.02$ $\mathrm{mm} . * P<.05$ versus placebo.

expression in human venous tissue and SMCs supports the potential for bidirectional cross-talk between MR and AT1R in the human vein as well. ${ }^{6}$

In this study, endogenous MR in human venous SMCs was activated transcriptionally by concentrations of aldosterone similar to those found in normal patient populations. ${ }^{15}$ Epidemiologic studies demonstrate that, in individuals with vascular disease, higher levels of aldosterone-even within the normal range-are associated with a nearly 2.5 -fold increase in cardiovascular ischemia and a 3.5-fold increase in cardiovascular death. ${ }^{18}$ In arterial SMCs and endothelial cells, aldosterone and the MR upregulate pathways that promote adverse vascular remodeling in response to injury, including medial hypertrophy and atherosclerosis. ${ }^{6,8}$ Given that the biologic processes leading to adverse vein graft remodeling are much like those seen in arterial injury, ${ }^{3,8}$ these findings support that MR activation could play an important role in vein graft remodeling.

Multiple mouse vein graft models have been developed. Here we used the IVC-to-abdominal aorta technique originally described by Salzberg and coworkers ${ }^{5}$ because the hemodynamics of the end-to-end anastomoses, ratio of graft to host vessel diameters, lack of foreign external support materials, and remodeling processes are all similar to current human surgical techniques and pathologies. ${ }^{5,19}$ Using this model, we demonstrate that administration of the MR antagonist spironolactone reduces focal vein graft thickening dramatically. This focal pattern of remodeling is particularly disruptive to hemodynamic flow and is the most frequent cause of vein graft failure. ${ }^{20}$ The vasculoprotective effects of RAAS blockade are traditionally thought to be the result of reduced blood pressures achieved through inhibition of renal MR. However, numerous clinical trials of RAAS antagonists have demonstrated cardiovascular benefits that exceed the modest reduction in blood pressure. ${ }^{6,21}$ Consistent with previous findings, ${ }^{13}$ the dose of spironolactone used did not change blood pressure significantly (data not shown), supporting a direct protective effect of MR antagonism on the grafted vein. The decreased vessel thickness observed with spironolactone treatment is accompanied by a concomitant reduction in vessel fibrosis. Aldosterone promotes arterial fibrosis in response to injury $^{6,8}$ and the MR regulates directly a number of profibrotic genes in SMCs and arteries, including type 1 and type 3 collagens and connective tissue growth factor. ${ }^{7,11}$ The role of these vascular MR-regulated fibrosis genes in vein graft remodeling and fibrosis warrants further exploration.

The source and type of cells that account for wall thickening as a result of vein graft remodeling is not clear, although prior studies have focused on SMC hyperplasia as the predominant contributor. Here, we observed no MR-mediated changes in graft SMC hyperplasia or cell number; rather, we saw that reduced graft thickness 
resulting from spironolactone treatment is driven, at least in part, by decreased inflammatory cell infiltration. Clinical and animal studies also support a role for inflammation in early vein graft remodeling. In patients undergoing lower extremity bypass surgery, markers of systemic inflammation (C-reactive protein) correlate with the degree of vein graft remodeling after 1 month. ${ }^{17}$ Consistent with this finding, blockade of monocyte chemoattractant factor, a proinflammatory molecule upregulated by aldosterone in the setting of vascular disease, ${ }^{6}$ inhibits vein graft remodeling in a canine model. ${ }^{22}$ We conclude that MR-mediated vascular inflammation may be an important component of vein graft remodeling. It has also been shown that AT1R blockade attenuates arterial remodeling by reducing inflammatory-like progenitor cells. ${ }^{23}$ Thus, inflammatory cell recruitment may be a common mechanism in RAASmediated vein graft remodeling.

This study has several important limitations that suggest future studies. Although we demonstrate a significant reduction in vein graft thickening, fibrosis, and inflammation in spironolactone-treated mice, this study is, necessarily, descriptive and further studies are needed to explore the molecular mechanisms involved in these processes. The use of a mouse vein graft model with a transplanted donor vein will allow for future studies using genetically altered donor and recipient mice to investigate the mechanisms. Although MR antagonist drugs are generally well tolerated, the overall effort, potential risk, and cost of doing a human randomized, controlled trial are not insubstantial, and thus additional data would be helpful to justify such a trial. This would include additional preclinical studies of MR antagonism in larger animal models such as the rabbit or pig model, as well as testing of a more selective MR antagonist, such as eplerenone, to support the mechanism further. Finally, we demonstrate expression of MR in human saphenous vein specimens from patients with diverse clinical characteristics and cardiac risk factors; however, future studies would require a much larger sample size to identify specific clinical characteristics that correlate with venous MR activation and would thus identify the patients most likely to benefit from MR antagonist therapy in a clinical trial.

In summary, vein graft surgery for obstructive coronary or peripheral vascular disease remains an evidenced-based treatment for a large patient population but is limited by a lack of graft durability with no effective therapy. ${ }^{5,24,25}$ This study implicates the MR in vein graft pathobiology in humans and demonstrates beneficial effects on graft remodeling using the clinically available MR antagonist in a mouse model. This study provides the first preclinical data in support of a clinical trial using an MR antagonist, started at the time of arterial bypass surgery using a venous conduit, to improve graft patency. Although further studies are needed to characterize the mechanism of MR-mediated vein graft remodeling and the patient populations most likely to benefit from MR inhibition, the long history of safety and cardiovascular benefit afforded by MR antagonists in patients with cardiovascular disease supports great potential for clinical translation of this study.

We thank Celso-Gomez Sanchez for the generous gift of MR monoclonal antibodies; Pilar Alcaide for assistance with inflammatory cell quantification; Heather Nickerson, Wendy Baur, and Brian Lin for technical assistance; and Greg Imbrie for helpful thoughts and discussions.

\section{References}

1. Zwolak RM, Adams MC, Clowes AW. Kinetics of vein graft hyperplasia: association with tangential stress. J Vasc Surg. 1987;5:126-36.

2. Parang P, Arora R. Coronary vein graft disease: pathogenesis and prevention. Can J Cardiol. 2009;25:e57-62.

3. Westerband A, Mills JL, Marek JM, Heimark RL, Hunter GC, Williams SK. Immunocytochemical determination of cell type and proliferation rate in human vein graft stenoses. J Vasc Surg. 1997;25:64-73.

4. Hosono M, Euda M, Suehiro S, Sasaki Y, Shibata T, Hattori K, et al. Neointimal formation at the sites of anastomosis of the internal thoracic artery grafts after coronary artery bypass grafting in human subjects: an immunohistochemical analysis. J Thorac Cardiovasc Surg. 2000;120:319-28.

5. Salzberg SP, Filsoufi F, Anyanwu A, von HK, Karlof E, Carpentier A, et al. Increased neointimal formation after surgical vein grafting in a murine model of type 2 diabetes. Circulation. 2006;114:I302-7.

6. McCurley A, Jaffe IZ. Mineralocorticoid receptors in vascular function and disease. Mol Cell Endocrinol. 2012;350:256-65.

7. Jaffe IZ, Mendelsohn ME. Angiotensin II and aldosterone regulate gene transcription via functional mineralocorticoid receptors in human coronary artery smooth muscle cells. Circ Res. 2005;96:643-50.

8. Jaffe IZ, Newfell BG, Aronovitz M, Mohammad NN, McGraw AP, Perrault RE, et al. Placental growth factor mediates aldosterone-dependent vascular injury in mice. J Clin Invest. 2010;120:3891-900.

9. Bafford R, Sui XX, Park M, Miyahara T, Newfell BG, Jaffe IZ, et al. Mineralocorticoid receptor expression in human venous smooth muscle cells: a potential role for aldosterone signaling in vein graft arterialization. Am J Phys Heart Circ Phys. 2011;301:H41-7.

10. Karas RH, Patterson BL, Mendelsohn ME. Human vascular smooth muscle cells contain functional estrogen receptor. Circulation. 1994;89:1943-50.

11. Newfell BG, Iyer LK, Mohammad NN, McGraw AP, Ehsan A, Rosano G, et al. Aldosterone regulates vascular gene transcription via oxidative stressdependent and -independent pathways. Arterioscler Thromb Vasc Biol. 2011; 31:1871-80.

12. Gomez-Sanchez CE, de Rodriguez AF, Romero DG, Estess J, Warden MP, Gomez-Sanchez MT, et al. Development of a panel of monoclonal antibodies against a mineralocorticoid receptor. Endocrinology. 2006;147: 1343-8.

13. Cassis LA, Helton MJ, Howatt DA, King VL, Daugherty A. Aldosterone does not mediate angiotensin II-induced atherosclerosis and abdominal aortic aneurysms. Br J Pharmacol. 2005; 144:443-8.

14. Sullivan TR Jr, Karas RH, Aronovitz M, Faller GT, Ziar JP, Smith JJ, et al. Estrogen inhibits the response-to-injury in a mouse carotid artery model. J Clin Invest. 1995;96:2482-8.

15. Vasan RS, Evans JC, Larson MG, Wilson PWF, Meigs JB, Rifai N, et al. Serum aldosterone and the incidence of hypertension in nonhypertensive persons. $N$ Engl J Med. 2004;351:33-41.

16. Angelina GD, Bryan AJ, Williams HM, Soyombo AA, Williams A, Tovey J, et al. Time-course of medial and intimal thickening in pig venous arterial grafts: relationship to endothelial injury and cholesterol accumulation. J Thorac Cardiovasc Surg. 1992;103:1093-103.

17. Owens CD, Rybicki FJ, Wake N, Schanzer A, Mitsouras D, GerhardHerman MD, et al. Early remodeling of lower extremity vein grafts: inflammation influences biomechanical adaptation. J Vasc Surg. 2008;47:1235-42.

18. Ivanes F, Susen S, Mouquet F, Pigny P, Cuilleret F, Sautiere K, et al. Aldosterone, mortality, and acute ischaemic events in coronary artery disease patients outside the setting of acute myocardial infarction or heart failure. Eur Heart J. 2012;33: 191-202. 
19. Yu P, Nguyen BT, Tao M, Campagna C, Ozaki CK. Rationale and practical techniques for mouse models of early vein graft adaptations. J Vasc Surg. 2010;52: 444-52.

20. McGah PM, Leotta DF, Beach KW, Zierler RE, Riley JJ, Aliseda A. Hemodynamic conditions in a failing peripheral artery bypass graft. $J$ Vasc Surg. May 1, 2012 [Epub ahead of print].

21. Pitt B, Remme W, Zannad F, Neaton J, Martinez F, Roniker B, et al. Eplerenone, a selective aldosterone blocker, in patients with left ventricular dysfunction after myocardial infarction. N Engl J Med. 2003;348:1309-21.

22. Tatewaki H, Egashira K, Kimura S, Nishida T, Morita S, Tominaga R. Blockade of monocyte chemoattractant protein-1 by adenoviral gene transfer inhibits experimental vein graft neointimal formation. J Vasc Surg. 2007;45:1236-43.
23. Ohtani K, Egashira K, Ihara Y, Nakano K, Funakoshi K, Zhao G, et al. Angiotensin II type 1 receptor blockade attenuates in-stent restenosis by inhibiting inflammation and progenitor cells. Hypertension. 2006;48: 664-70.

24. Ehsan A, Mann MJ, Dell'Acqua G, Dzau VJ. Long-term stabilization of vein graft wall architecture and prolonged resistance to experimental atherosclerosis after E2F decoy oligonucleotide gene therapy. J Thorac Cardiovasc Surg. 2001; 121:714-22.

25. Schepers A, de Vries MR, van Leuven CJ, Grimbergen JM, Holers VM, Daha MR, et al. Inhibition of complement component $\mathrm{C} 3$ reduces vein graft atherosclerosis in apolipoprotein E3-Leiden transgenic mice. Circulation. 2006; 114:2831-8 
TABLE E1. Primer sequences used in this study

\begin{tabular}{ll}
\hline \multicolumn{1}{c}{ Primer } & \multicolumn{1}{c}{ Sequence (5' to $\mathbf{3}^{\prime}$ ) } \\
\hline GAPDH forward & TGG GTG TGA ACC ATG AGA AG \\
GAPDH reverse & GCT AAG CAG TTG GTG GTG C \\
MR forward & CCG GCT TTG ATG GTA ACT GT \\
MR reverse & CCC CAA CAA TAG CAG AGG AA \\
ATR1 forward & ACT TTG CCA CTA TGG GCT GTC \\
ATR1 reverse & GTA CAG GTT GAA ACT GAC GCT \\
ACE1 forward & ACC TCA ACC TGC ATG CCT AC \\
ACE1 reverse & AGG GCA CCA CCA AGT CAT AG \\
AS forward & ACC TGG AGA TGC ACC AGA C \\
AS reverse & GGC CCA TTC AAC AAG AAC ACG \\
ATNG forward & GCT GCT GAG AAG ATT GAC AGG \\
ATNG reverse & TTT GCC TTA CCT TGG AAG TGG \\
GR forward & CTG TCG CTT CTC AAT CAG ACT C \\
GR reverse & GCA TTG CTT ACT GAG CCT TTT G \\
$11 \beta$ HSD2 forward & TCT GGT TTT GGC AAG GAG AC \\
$11 \beta$ HSD2 reverse & GCC AAA GAA ATT CAC CTC CA \\
Renin forward & CCG TGA TCC TCA CCA ACT ACA \\
Renin reverse & GCA CCC AAA CAT TGG ACG AAC \\
\hline GAPDH, Glyceraldehyde-3-phosphate dehydrogenase; $M R$, mineralocorticoid recep- \\
tor; ATR1, angiotensin type 1 receptor; ACE1, angiotensin-converting enzyme type 1; \\
AS, aldosterone synthase; $A T N G$, angiotensinogen; $G R$, glucocorticoid receptor; \\
$11 \beta H S D 2,11-\beta$-hydroxysteroid dehydrogenase-2.
\end{tabular}

